\title{
Sensitivity Analysis of Temperature Control Parameters and Study of the Simultaneous Cooling Zone during Dam Construction in High-Altitude Regions
}

\author{
Zhenhong Wang, ${ }^{1}$ Yi Liu, ${ }^{1,2}$ Guoxin Zhang, ${ }^{1,2}$ and Shuping Yu ${ }^{1,3}$ \\ ${ }^{1}$ Department of Structures and Materials, China Institute of Water Resources and Hydropower Research, Beijing 100038, China \\ ${ }^{2}$ State Key Laboratory of Simulation and Regulation of Water Cycle in River Basin, China Institute of Water Resources \\ and Hydropower Research, Beijing 100038, China \\ ${ }^{3}$ Henan Yellow River Reconnaissance, Design and Research Institute Beijing Branch, Beijing 100073, China
}

Correspondence should be addressed to Zhenhong Wang; faithzhen@126.com

Received 26 August 2014; Revised 18 December 2014; Accepted 2 January 2015

Academic Editor: Weizhong Dai

\begin{abstract}
Copyright ( 2015 Zhenhong Wang et al. This is an open access article distributed under the Creative Commons Attribution License, which permits unrestricted use, distribution, and reproduction in any medium, provided the original work is properly cited.

There are unprecedented difficulties in building concrete gravity dams in the high altitude province Tibet with problems induced by lack of experience and technologies and unique weather conditions, as well as the adoption of construction materials that are disadvantageous to temperature control and crack prevention. Based on the understandings of the mentioned problems and leveraging the need of building gravity dam in Tibet, 3D finite element method is used to study the temperature control and crack prevention of the dam during construction. The calculation under recommend temperature control measures and standards shows that the height and number of simultaneous cooling zone have the more obvious influencers on concrete stress; therefore, it is suggested to increase the height of simultaneous cooling zone to decrease the stress caused by temperature gradient of adjoin layers so as to raise the safety level of the whole project. The research methods and ideas used on this project have significant values and can be taken as references in similar projects in high altitude regions.
\end{abstract}

\section{Introduction}

Dams have been successfully built around the world, especially in low-altitude regions $[1,2]$. In high-altitude regions, such as Tibet, however, the lack of experiences in dam-related technologies and systematic theories introduces challenges in building dams. A high altitude implies a complicated climate that features dry and thin air, strong sun radiation, and severe temperature difference between day and night $[3,4]$. Compared with building dams in low-altitude regions that have warm and humid air and a small temperature difference between day and night, building dams in highaltitude regions requires specific, straightforward, and tailored measures and standards for temperature control and crack prevention.

Cracks in large volumes of concrete are always a challenge in the field of engineering. Many engineering cases involve cracks caused by temperature at different levels in largevolume concrete structures, such as dams, during and after construction. These cracks make structures appear weak, and they severely affect durability and safety [5-9]. Because temperature-induced cracking problems continue to be a major challenge in engineering, designers and builders also continue to study large-volume concrete projects and develop appropriate temperature control measures and standards to decrease temperature stress and avoid or reduce cracks. This study focuses on the Jiexu Dam, a gravity dam being built in Tibet. To analyze the sensitivities of conditions and parameters during the construction process in the region, the 3D finite element method [10-13] is used. The discussion concludes by presenting rules on the conditions and parameters that affect temperature stress in the dam. This study considers heat transfer and the hardening development process of concrete [14-17], the shrinkage deformation caused 
by temperature changes in concrete $[18,19]$, and the pipe cooling measures of concrete [20]. From the findings and information obtained from similar projects, a set of measures and standards suitable for dam construction in high-altitude regions are proposed to guide the safe construction of dams.

\section{Calculation Principles and Methods}

2.1. Differential Equation for Heat Conduction. Differential equation [21] (1) applies to the temperature field of even and isotropic homogeneous solid:

$$
\frac{\partial^{2} T}{\partial x^{2}}+\frac{\partial^{2} T}{\partial y^{2}}+\frac{\partial^{2} T}{\partial z^{2}}+\frac{1}{\alpha}\left(\frac{\partial \theta}{\partial \tau}-\frac{\partial T}{\partial \tau}\right)=0
$$

In the equation, $T$ stands for temperature $\left({ }^{\circ} \mathrm{C}\right), x, y$, and $z$ are the three coordinates of a point (m), $\alpha$ stands for thermal diffusivity $\left(\mathrm{m}^{2} \cdot \mathrm{h}^{-1}\right), \theta$ is the adiabatic temperature rise of concrete $\left({ }^{\circ} \mathrm{C}\right)$, and $\tau$ stands for maturity (day).

The principle of minimum gravitational energy indicates that the differential equation for heat conduction (1) can be converted: temperature $T(x, y, z, \tau)$ is set as the initial temperature $T_{0}(x, y, z)$ when $\tau=0$; the heat conduction matrix $[H]^{e}$, heat capacity matrix $[R]^{e}$, and temperature load array $\{F\}^{e}$ are achieved when the extremum is given for each boundary and through spatial discretization and difference in the time domain. After integration, the partial differential of temperature at each nodal is determined:

$$
\left\{\frac{\partial I}{\partial T}\right\}=[H]\{T\}+[R] \frac{\partial\{T\}}{\partial \tau}+\{F\}=0 .
$$

In the above equation, $H_{i j}=\sum H_{i j}^{e}, R_{i j}=\sum R_{i j}^{e}, F_{i}=\sum F_{i}^{e}$.

Equation (2) is a set of linear differential equations with $\tau$ as the independent variable. In the equation, $R$ is the heat capacity matrix, $H$ is the heat conduction matrix, $F$ is the temperature load column matrix, $T$ is the nodal temperature array, and $\partial\{T\} / \partial \tau$ is the derivative array of nodal temperature against time.

2.2. Finite Element Method of the Stress Field. The strain increment of concrete under complex stress includes the elastic strain increment, creep strain increment, temperature strain increment, dry shrinkage strain increment, and autogenous volume strain increment [21]; thus,

$$
\left\{\Delta \varepsilon_{n}\right\}=\left\{\Delta \varepsilon_{n}^{e}\right\}+\left\{\Delta \varepsilon_{n}^{c}\right\}+\left\{\Delta \varepsilon_{n}^{T}\right\}+\left\{\Delta \varepsilon_{n}^{s}\right\}+\left\{\varepsilon_{n}^{0}\right\},
$$

where $\left\{\Delta \varepsilon_{n}^{e}\right\}$ is the elastic strain increment, $\left\{\Delta \varepsilon_{n}^{c}\right\}$ is the creep strain increment, $\left\{\Delta \varepsilon_{n}^{T}\right\}$ is the temperature strain increment, $\left\{\Delta \varepsilon_{n}^{s}\right\}$ is the dry shrinkage strain increment, and $\left\{\Delta \varepsilon_{n}^{0}\right\}$ is the autogenous volume strain increment.

We obtain a finite element governing equation of any time interval $\Delta t_{i}$ on the area $R_{i}$ from the physical equation, the geometric equation, and the equilibrium equation as follows:

$$
\left[K_{i}\right]\{\Delta \delta\}_{i}=\left\{\Delta P_{i}^{G}\right\}+\left\{\Delta P_{i}^{C}\right\}+\left\{\Delta P_{i}^{T}\right\}+\left\{\Delta P_{i}^{S}\right\}+\left\{\Delta P_{i}^{0}\right\},
$$

where $\left\{\Delta \delta_{i}\right\}$ is the displacement increment of all nodes in three directions in area $R_{i}$ and $\left\{\Delta P_{i}^{G}\right\},\left\{\Delta P_{i}^{C}\right\},\left\{\Delta P_{i}^{T}\right\},\left\{\Delta P_{i}^{S}\right\}$, and $\left\{\Delta P_{i}^{0}\right\}$ are the equivalent nodal force increment caused by the external load, creep, temperature change, dry shrinkage, and autogenous volume deformation within $\Delta t_{i}$, respectively.

2.3. The 3D Finite Element Method Software SAPTIS. The Structure Analysis Program for Temperature and Induced Stress (SAPTIS) software package facilitates the FORTRAN language-programmed, large-scale multifield simulation, and nonlinear analysis. The software is used to simulate the calculation of temperature, stress, seepage, and deformation, among other factors, in the entire process of foundation excavation, pouring process, water storage process, and longterm operation of concrete dams. The main features of the program include the excavation and pouring simulation method, the hydration heat model, the water cooled model, the temperature boundary conditions, the elastic modulus model, the creep model, autogenous volume deformation, and $\mathrm{MgO}$ concrete characteristics in the entire simulation process of dams.

The program has a rich element library. 3D problems include 8-20 variable node hexahedron isoparametric elements, 6-15 variable node pentahedron isoparametric elements, and 8-node hexahedron isoparametric elements, as well as bar elements, joint elements, and contact elements, to name a few. SAPTIS has a variety of solvers. The direct solution method or the iterative solution method can be used to solve large linear equations. SAPTIS is characterized by its high speed and small memory capacity. It can use a computer to conduct simulation analysis, as well as general structural stress and deformation analysis of large concrete structures; it can also use a server for parallel computing. The software is successfully applied to more than 50 large and medium concrete dams of the Three Gorges, Ertan, Longtan, Xiaowan, Xiluodu, Jinping, Danjiangkou, and other dams, as well as for the simulation analysis of the temperature and stress fields of other structures. Favorable economic benefits are achieved as a result.

\subsubsection{Adiabatic Temperature Rise Model. Consider}

$$
\begin{aligned}
& \text { Exponential Model: } \theta(\tau)=\theta_{0}\left(1-e^{-\alpha \tau^{b}}\right), \\
& \text { Hyperbolic Model: } \theta(\tau)=\frac{\theta_{0} \tau}{(\alpha+\tau)}, \\
& \text { Combination Model: } \theta=\left\{\begin{array}{l}
\theta_{0}\left(1-e^{-a \tau^{b}}\right) \\
\frac{\theta_{0} \tau}{n+\tau},
\end{array}\right.
\end{aligned}
$$

where $\theta(\tau)$ is the adiabatic temperature rise of concrete $\left({ }^{\circ} \mathrm{C}\right)$, $\theta_{0}$ is the final adiabatic temperature rise $\left({ }^{\circ} \mathrm{C}\right), a$ and $b$ are the law parameters of the adiabatic temperature rise, and $n$ is a constant. 


\subsubsection{Elastic Modulus Model}

Exponential Model: $E(\tau)=E_{0}+E_{c}\left(1-e^{-\alpha \tau^{\beta}}\right)$,

Hyperbolic Model: $E(\tau)=E_{0}+\frac{E_{c} \tau}{(\tau+\alpha)}$,

where $E_{0}$ is the initial elastic modulus of concrete $(\mathrm{GPa}), E_{c}$ is the final elastic modulus of concrete $(\mathrm{GPa}), \tau$ is the age of concrete, and $\alpha$ and $\beta$ are the variation coefficients of the elastic modulus of concrete.

\subsubsection{Creep Model}

Model 1. Consider

$$
\begin{aligned}
C(t, \tau)= & \left(A_{1}+\frac{A_{2}}{\tau}+\frac{A_{3}}{\tau^{2}}\right)\left(1-e^{-k_{1}(t-\tau)}\right)+\left(B_{1}+\frac{B_{2}}{\tau}+\frac{B_{3}}{\tau^{2}}\right) \\
& \cdot\left(1-e^{-k_{2}(t-\tau)}\right)+D e^{-k_{3}(t-\tau)}\left(1-e^{-k_{3}(t-\tau)}\right) .
\end{aligned}
$$

Model 2. Consider

$$
\begin{aligned}
C(t, \tau)= & \left(A_{1}+A_{2} \tau^{-\alpha_{1}}\right)\left(1-e^{-k_{1}(t-\tau)}\right)+\left(B_{1}+B_{2} \tau^{-\alpha_{2}}\right) \\
& \cdot\left(1-e^{-k_{2}(t-\tau)}\right)+D e^{-k_{3} t}\left(1-e^{-k_{3}(t-\tau)}\right)
\end{aligned}
$$

where $C(t, \tau)$ is the specific creep, $10^{-6} / \mathrm{MPa} ; k_{1}, k_{2}$, and $k_{3}$ are the creep rate parameters; $A_{1}, A_{2}, A_{3}, B_{1}, B_{2}, B_{3}$, and $D$ are the specific creep parameters, $10^{-6} / \mathrm{MPa}$; $t$ is the time (day); and $\tau$ is the loading age (day).

2.3.4. Autogenous Volume Model. Autogenous volume deformation is determined by the direct input of experimental data and the deformation values between the two experimental ages through spline function interpolation.

2.3.5. Water Cooling Model. The contact surfaces of concrete with air, water, rocks, and other media transfer heat and have a cooling effect. With the pipe cooling effect considered, the problem is complex, such that it cannot be solved by theoretical methods; accurately solving it with the finite element method is also difficult. An approximate solution can be obtained only through consideration of the cooling water pipes as a negative heat source and of the function of the cooling water pipes, on average. If the initial temperature of concrete is set to $T_{0}$, the intake water temperature is set to $T_{w}$, the final adiabatic temperature rise of concrete is set to $\theta_{0}$, and the time is set to $t$; the average temperature of concrete is calculated as follows:

$$
T(t)=T_{w}+\left(T_{0}-T_{w}\right) \Phi(t)+\theta_{0} \Psi(t) .
$$

Therefore, the equivalent thermal conductivity equation of concrete is as follows:

$$
\frac{\partial T}{\partial t}=a \nabla^{2} T+\left(T_{0}-T_{w}\right) \frac{\partial \Phi}{\partial t}+\theta_{0} \frac{\partial \Psi}{\partial t}
$$

where $\Phi$ represents the pipe cooling effect and $\Psi$ represents the adiabatic temperature rise effect. The details are discussed in [21].

The equation indicates that the problem can be simplified, and the common cooling effect of cooling water pipes can be approximately calculated with the existing finite element program and computational grid.

\section{Overview of the Gravity Dam}

3.1. Project Overview. Jiexu Hydropower Station is located at the boarder of Sangri County and Jiacha County in Shannan Region of the Tibet Autonomous Region. The station is a third-stage power plant in the gorge section from Sangri County to Jiacha County along midstream of Yarlung Tsangpo River. It is $7 \mathrm{~km}$ away from a planned Dagu Hydropower Plant in the upstream and $18 \mathrm{~km}$ away from the Zangmu Hydropower Plant currently being built in the downstream. Jiexu Hydropower Plant is primarily designed for power generation. In the up dam site, the catchment area is $157,407 \mathrm{~km}^{2}$, and the average flow at the dam site is $1,010 \mathrm{~m}^{3} \cdot \mathrm{s}^{-1}$. The standard impounded level of the dam is at $3,374 \mathrm{~m}$, and the storage capacity is 47.48 million $\mathrm{m}^{3}$, with an adjusted storage capacity of 9.85 million $\mathrm{m}^{3}$. Four generators are installed with a total capacity of $560 \mathrm{MW}$ and a firm capacity of $152 \mathrm{MW}$. The average power generation volume is 2,755.6 million kWh.

The Jiexu Hydropower Station river dam is a concrete gravity dam. From left to right are a left bank waterretaining dam section, diversion dam section, bottom outlet dam section, overflow dam section, and right bank waterretaining dam section. The dam crest is $340 \mathrm{~m}$ long, the crest elevation is $3,378.0 \mathrm{~m}$, the maximum dam height is $117.0 \mathrm{~m}$, the widest bottom of the dam is $99.8 \mathrm{~m}$, and the total volume of dam concrete is around 1.64 million $\mathrm{m}^{3}$. The largest dam section is $32.5 \mathrm{~m}$ wide. The project is constructed in 14 dam sections. The dam has five flood release orifices with a dimension of $14 \mathrm{~m} \times 21.5 \mathrm{~m}$, one bottom outlet for flood release with a dimension of $5 \mathrm{~m} \times 8 \mathrm{~m}$, and four power generation water inlets. The dam is a complicated structure, with its construction ongoing for a year now; it has a long construction cycle and involves complicated construction conditions.

\subsection{Engineering Difficulties}

(1) Special geological conditions make temperature control challenging. The project is located in Tibet, a high-altitude region. Therefore, it is characterized by thin air, dry climate, strong solar radiation, severe temperature difference between day and night, and large monthly average temperature variance. Such a climate is disadvantageous in controlling temperature to prevent cracks on concrete.

(2) The construction materials used in building the dam are not helpful for temperature control and crack prevention. The composition of concrete used for the project shows that within the same region and similar 
TABLE 1: Comparison of the key temperature control parameters of Jiexu and Zangmu.

\begin{tabular}{|c|c|c|c|c|c|c|}
\hline Project & $\begin{array}{l}\text { Thermal expansion } \\
\text { coefficient }\left[{ }^{\circ} \mathrm{C}^{-1}\right]\end{array}$ & $\begin{array}{c}\text { Dam concrete } \\
\text { adiabatic } \\
\text { temperature rise }\left[{ }^{\circ} \mathrm{C}\right]\end{array}$ & $\begin{array}{c}\text { Autogenetic } \\
\text { volume } \\
\text { deformation }\left[10^{-6}\right]\end{array}$ & $\begin{array}{l}90 \mathrm{~d} \text { modulus of } \\
\text { elasticity [GPa] }\end{array}$ & $\begin{array}{c}90 \mathrm{~d} \text { tensile } \\
\text { strength }[\mathrm{MPa}]\end{array}$ & $\begin{array}{c}90 \mathrm{~d} \text { ultimate } \\
\text { tensile } \\
\text { appreciation }\left[10^{-4}\right]\end{array}$ \\
\hline $\begin{array}{l}\text { Jiexu Gravity } \\
\text { Dam }\end{array}$ & $9.0 \times 10^{-6}$ & 26.3 & -20.0 & 20.2 & 2.03 & 1.09 \\
\hline $\begin{array}{l}\text { Zangmu Gravity } \\
\text { Dam }\end{array}$ & $7.4 \times 10^{-6}$ & 23.8 & -19.9 & 20.2 & 2.14 & 1.12 \\
\hline
\end{tabular}

structure, the coefficient of thermal expansion of concrete is $9.0 \times 10^{-6 \circ} \mathrm{C}^{-1}$, and the adiabatic temperature rise is $26.3^{\circ} \mathrm{C}$, which is 1.22 times and $3^{\circ} \mathrm{C}$ higher than those of Zangmu, respectively. However, the modulus of elasticity and tensile strength in both stations are similar. The material parameters used for the Jiexu project are disadvantageous for crack prevention, and temperature control in Jiexu is also more difficult than that in Zangmu. Table 1 shows a comparison of the key temperature control parameters of Jiexu and Zangmu.

\subsection{Calculation Model and Boundary Conditions}

3.3.1. Computational Grid and Boundary Conditions. Boundary conditions of the temperature field: the bottom surface and surrounding sides of the foundation are adiabatic boundaries; the upper surface of the foundation is the third boundary that considers temperature and solar radiation; both sides of the dam are adiabatic boundaries; the upstream face and the downstream face of the dam before impoundment are the third boundaries that consider temperature and solar radiation; and the upstream face and the downstream face of the dam after impoundment are the first boundaries, and their temperature is the reservoir temperature.

Boundary conditions of the stress field: the bottom surface of the foundation is regarded as a fixed surface; the surrounding sides of the foundation are supported in the normal direction, whereas the other boundary faces are freely deformed faces. Because the ambient air temperature and water temperature considerably affect the upstream face and the downstream face of the dam and the temperature and stress gradients are large, a relatively dense grid is set. Figure 1 shows the simulation grid, and Figure 2 shows the boundary conditions of the simulation calculation model.

3.3.2. Calculation Parameter Model. The body of the dam uses four-graded concrete derived from the test data:

adiabatic temperature rise model of concrete: $T(t)=$ $(26.26 \times t) /(t+3.73),{ }^{\circ} \mathrm{C}$,

elastic modulus model of concrete: $E(t)=32.6 \times(1-$ $\left.e^{-0.38 t^{0.28}}\right), \mathrm{GPa}$.

The autogenous volume deformation of concrete uses the test data of Table 2 .

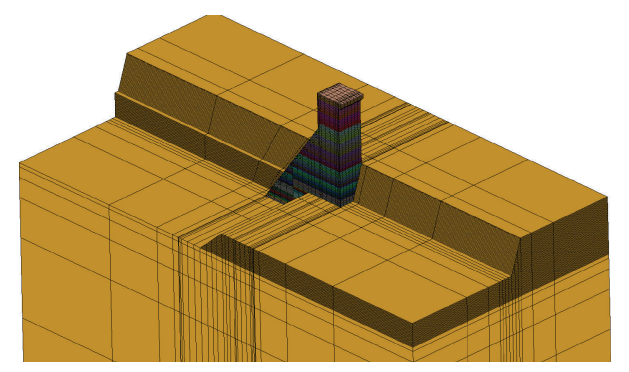

FIGURE 1: Simulation grid.

\section{Sensitivity Analyses of the Temperature Control Parameters of Dams in High- Altitude Regions}

4.1. Sensitivity Analysis of Pouring in Different Seasons. The high restraint zone of gravity dams is essential to temperature control, and it is also the most challenging aspect to deal with. This study mainly focused on the temperature and stress in the high restraint zone.

(1) Table 3 shows that, in pouring the concrete of the high restraint zone, the highest temperature is $26.3^{\circ} \mathrm{C}$ during summer, whereas it is $25.5^{\circ} \mathrm{C}$ and $24.5^{\circ} \mathrm{C}$ during autumn and winter, respectively. The highest temperature difference is large from season to season with the same temperature control measures. Water pipe cooling involves three stages: decrease in the highest temperature during the first stage, decrease in the control temperature rate and gradient during the middle stage, and cooling down to the joint grouting temperature during the second stage. Figure 3(a) shows that the temperature reasonably dropped (i.e., without rebounding or decreasing rapidly).

(2) The high restraint region has the strongest stress, with the maximum stress occurring during the second stage when the temperature drops to the target level. In general, the high restraint zone of concrete poured during the high-temperature season shows the highest maximum temperature, temperature difference, and maximum stress. In Tibet's Jiexu Station, the stress of concrete poured during autumn is higher than that poured during summer, which is against the general rule that the highest stress occurs during autumn. 


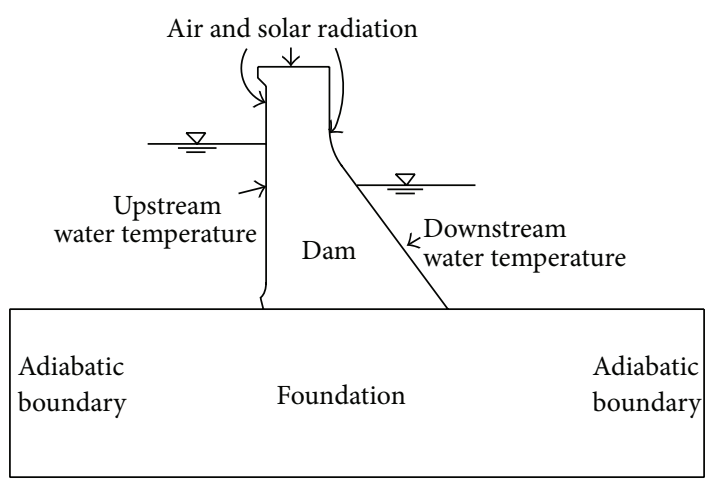

(a) Temperature boundary

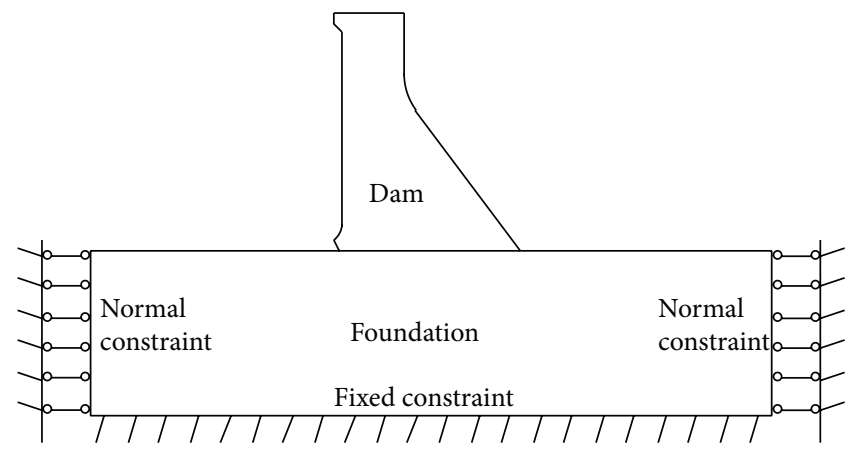

(b) Stress boundary

FIgURE 2: Boundary conditions of the simulation model.

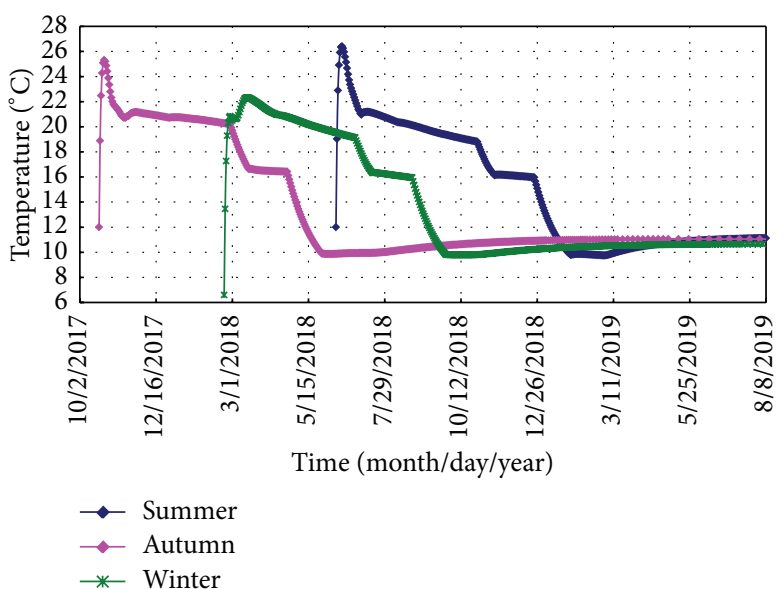

(a) Temperature

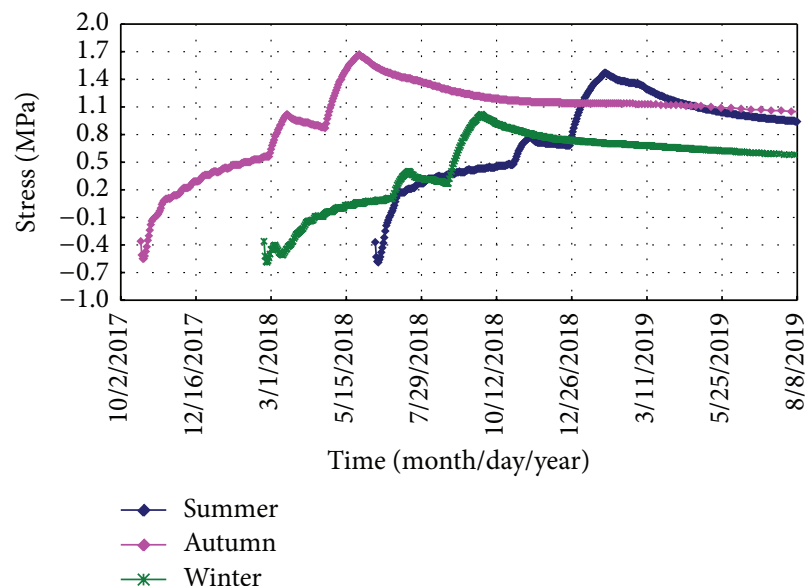

(b) Stress

FIGURE 3: Process curve of concrete temperature and stress at characteristic points in the basic restraint zone during pouring at different seasons.

TABLE 2: Autogenous volume deformation of concrete.

\begin{tabular}{lccccccccc}
\hline Age (day) & dat $\left(10^{-6}\right)$ & Age (day) & dat $\left(10^{-6}\right)$ & Age (day) & dat $\left(10^{-6}\right)$ & Age (day) & dat $\left(10^{-6}\right)$ & Age $($ day) & dat $\left(10^{-6}\right)$ \\
\hline 0 & 0.0 & 7 & 5.4 & 18 & -1.0 & 80 & -13.5 & 140 \\
1 & 0.0 & 8 & 3.5 & 28 & -5.4 & 93 & -14.6 & 150 \\
2 & 1.1 & 10 & 3.3 & 44 & -9.1 & 100 & -14.5 & -14.1 \\
3 & 0.9 & 11 & 3.3 & 56 & -10.2 & 110 & -14.9 & \\
4 & 2.4 & 14 & 1.1 & 63 & -11.6 & 120 & -14.9 & -14.8 \\
5 & 4.1 & 16 & 0.5 & 70 & -12.8 & 130 & & \\
\hline
\end{tabular}

Note. Negative values indicate that the autogenous volume deformation is of shrinkage type.

TABLE 3: Concrete temperature stress as affected by the pouring season.

\begin{tabular}{llcccccccc}
\hline $\begin{array}{l}\text { Starting } \\
\text { season }\end{array}$ & $\begin{array}{l}\text { Pouring } \\
\text { temperature } \\
\left({ }^{\circ} \mathrm{C}\right)\end{array}$ & $\begin{array}{c}\text { Water temperature }\left({ }^{\circ} \mathrm{C}\right) \\
\text { stage }\end{array}$ & $\begin{array}{c}\text { Middle } \\
\text { Stage }\end{array}$ & $\begin{array}{c}\text { Second } \\
\text { Stage }\end{array}$ & $\begin{array}{l}\text { Intervals } \\
(\text { day) }\end{array}$ & $\begin{array}{l}\text { Maximum temperature } \\
\text { in the high restraint zone } \\
\left({ }^{\circ} \mathrm{C}\right)\end{array}$ & $\begin{array}{c}\text { Maximum tensile stress in the } \\
\text { high restraint zone } \\
\text { Elevation } \\
(\mathrm{m})\end{array}$ & $\begin{array}{c}\text { Safety } \\
\text { coefficient }\end{array}$ \\
\hline Summer & $\leq 12$ & 8 & 12 & 7 & 10 & 26.3 & 1.45 & 3263.0 & 1.74 \\
Autumn & $\leq 12$ & 8 & 12 & 7 & 10 & 25.5 & 1.63 & 3264.5 & 1.55 \\
Winter & $\geq 6$ & 8 & 12 & 7 & 10 & 24.5 & 1.05 & 3264.5 & 2.41 \\
\hline
\end{tabular}

Note. (1) $\sigma_{x}$ is the along-river stress, and (2) $k$ is the safety coefficient. Strength control is designed based on 180 days; the tensile strength of third-grade concrete is $2.53 \mathrm{Mpa}$, whereas that of fourth-grade concrete is $2.73 \mathrm{Mpa}$. The same data are presented in Figure 3 . 


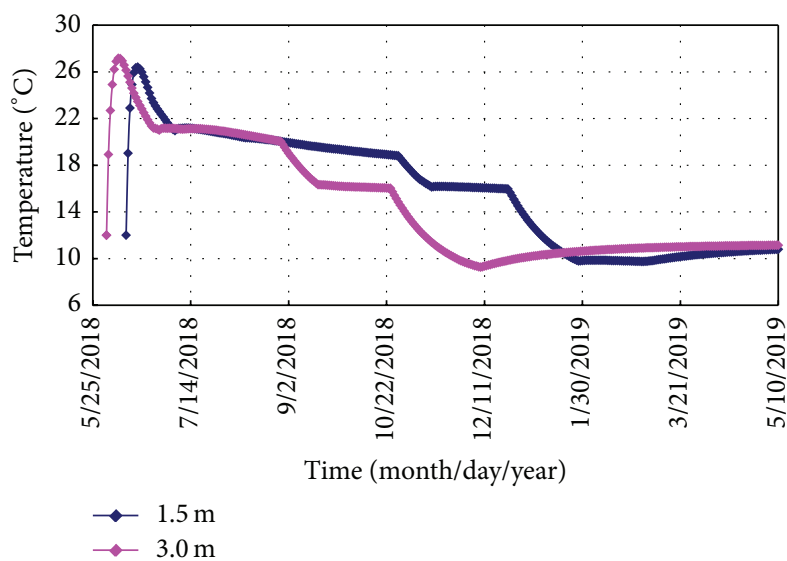

(a) Temperature

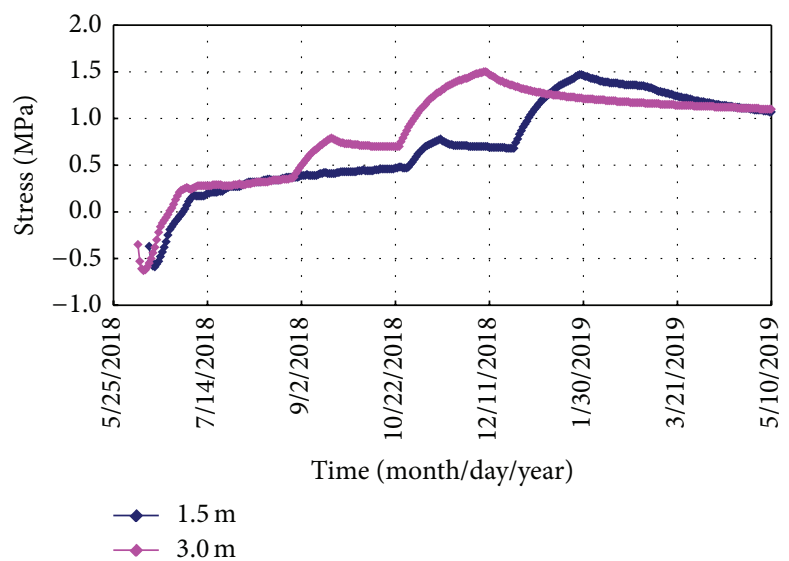

(b) Stress

FIgURE 4: Process curve of concrete temperature and stress in the high restraint zone with different pouring thicknesses.

TABLE 4: Effect of pouring thickness on temperature stress.

\begin{tabular}{llccrr}
\hline \multirow{2}{*}{ Start of pouring } & Thickness $(\mathrm{m})$ & \multicolumn{2}{c}{ Maximum temperature in } & \multicolumn{2}{c}{ Maximum tensile stress in the high restraint zone } \\
& & the high restraint zone $\left({ }^{\circ} \mathrm{C}\right)$ & $\sigma_{x}(\mathrm{Mpa})$ & Elevation $(\mathrm{m})$ & Safety coefficient $k$ \\
\hline \multirow{2}{*}{ June } & 1.5 & 26.3 & 1.45 & 3263 & 1.74 \\
& 3.0 & 29.2 & 1.48 & 3263 & 1.71 \\
\hline
\end{tabular}

Table 3 and Figure 3(b) show that the maximum alongriver stress of the high restraint zone during summer is $1.45 \mathrm{Mpa}$, which is lower than the $1.63 \mathrm{Mpa}$ value during autumn and is at its lowest during winter. Two reasons account for this phenomenon: (1) Jiexu Dam is located in an area where the air temperature drop is significant from October to December. The average air temperature in October is $10.4^{\circ} \mathrm{C}$, which drops to $0.7^{\circ} \mathrm{C}$ in December. During the beginning of pouring in autumn, a significant air temperature drop occurs, and until January of the following year, the drop is $10.1^{\circ} \mathrm{C}$; (2) the maximum concrete temperature of pouring during summer is higher than that during autumn, so the compressive stress reserve is also relatively large. The maximum concrete temperature of pouring during autumn is possibly lower than that of pouring during summer, but the concrete stress of pouring during autumn is higher than that of pouring during summer.

4.2. Sensitivity Analysis of Pouring Thickness. Pouring concrete at the high restraint zone causes the thickness to significantly affect temperature stress. A thick concrete pouring will have a high internal temperature, foundation temperature difference, and maximum stress. By contrast, a thin concrete pouring will have a low internal temperature, temperature difference, and stress, but it cannot be too thin. To analyze the stress involved, this study focuses on two situations in which the thickness is 1.5 and $3.0 \mathrm{~m}$.

(1) Table 4 and Figure 4(a) show that when concrete is poured during summer at $1.5 \mathrm{~m}$, the maximum temperature is $26.3^{\circ} \mathrm{C}$, and when the thickness is $3 \mathrm{~m}$, the maximum temperature is $29.2^{\circ} \mathrm{C}$, which is $2.9^{\circ} \mathrm{C}$ higher than $26.3^{\circ} \mathrm{C}$. Therefore, the air temperature during summer in Jiexu Dam is far lower than the internal temperature of concrete. A thick pouring will be disadvantageous to the production of heat, and this will cause the maximum temperature to increase.

(2) Figure 4(b) shows that the maximum concrete stress occurs at the end of the second stage of cooling; the temperature drops to the lowest temperature (target temperature). The difference in maximum temperature results in the variation in the foundation temperature, so a temperature difference at the joint grouting also occurs. Table 4 shows that the maximum stress is observed to be too high when the concrete poured is $3 \mathrm{~m}$ thick. The pouring thickness in the high restraint zone is recommended to be $1.5 \mathrm{~m}$, and concrete surface heat preservation should also be observed, especially when pouring is done during high- and low-temperature seasons.

4.3. Sensitivity Analysis of Pouring Intervals. The length of pouring intervals is a problem every constructor needs to address. This research mainly focuses on the effect of intervals on temperature and stress. The study considers situations in which the interval is 15,20 , and 28 days.

(1) Table 5 and Figure 5(a) indicate that the maximum internal temperature occurs from days 5 to day 7 . The correlation between the maximum temperature and the interval length is trivial when the pouring interval is from 15 days to 28 days. However, because of the effect of watering pipe cooling, the longer is the interval, the lower is the temperature at the bottom 


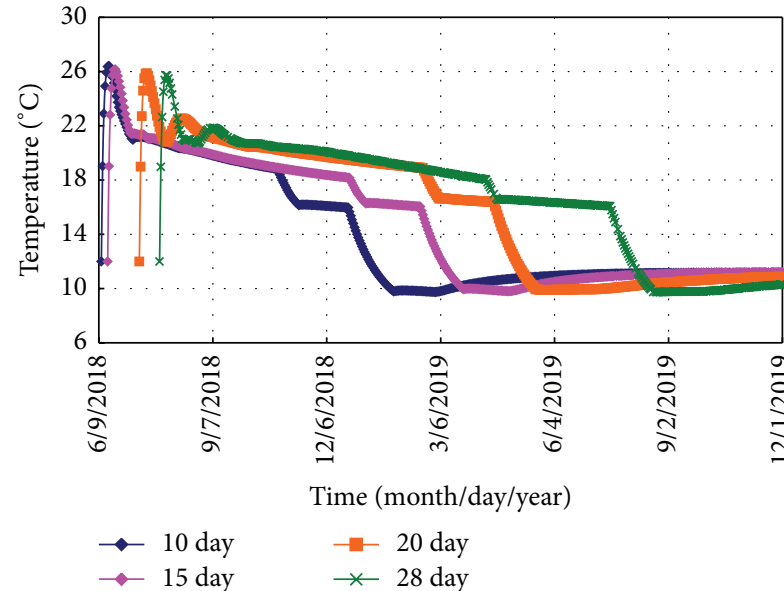

(a) Temperature

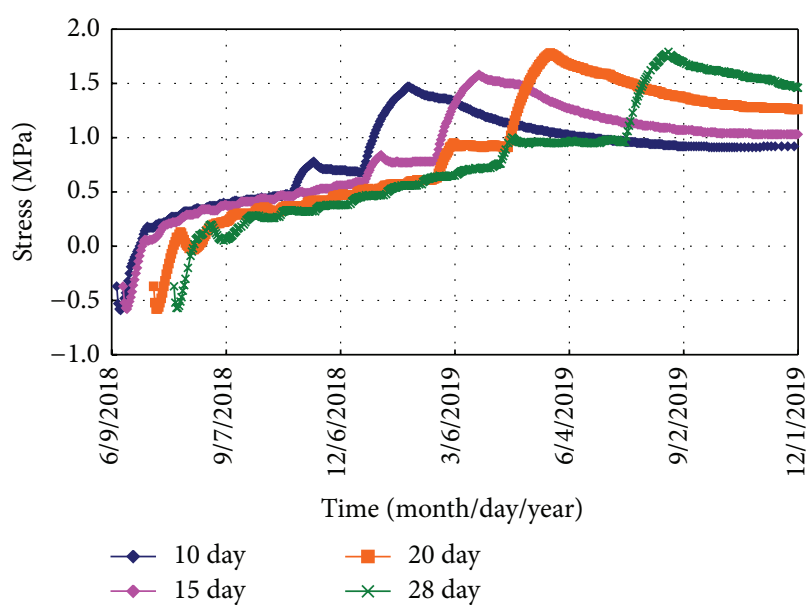

(b) Stress

FIGURE 5: Process curve of concrete temperature and stress in the basic restraint zone at different pouring intervals.

TABLE 5: Effect of pouring intervals on temperature stress.

\begin{tabular}{|c|c|c|c|c|c|c|c|}
\hline \multirow{2}{*}{$\begin{array}{l}\text { Interval } \\
\text { (day) }\end{array}$} & \multirow{2}{*}{$\begin{array}{l}\text { Maximum temperature in the } \\
\text { high restraint zone }\left({ }^{\circ} \mathrm{C}\right)\end{array}$} & \multicolumn{3}{|c|}{$\begin{array}{l}\text { Maximum tensile stress in } \\
\text { the high restraint zone }\end{array}$} & \multicolumn{3}{|c|}{$\begin{array}{l}\text { Maximum tensile stress in the low } \\
\text { restraint zone and the free zone }\end{array}$} \\
\hline & & $\sigma_{x}(\mathrm{Mpa})$ & $\begin{array}{l}\text { Elevation } \\
(\mathrm{m})\end{array}$ & $\begin{array}{c}\text { Safety } \\
\text { coefficient }\end{array}$ & $\sigma_{x}(\mathrm{Mpa})$ & $\begin{array}{l}\text { Elevation } \\
(\mathrm{m})\end{array}$ & $\begin{array}{c}\text { Safety } \\
\text { coefficien }\end{array}$ \\
\hline 10 & 26.3 & 1.45 & 3263 & 1.74 & 0.79 & 3283.0 & 3.00 \\
\hline 15 & 26.1 & 1.57 & 3263 & 1.61 & 0.77 & 3343.5 & 3.08 \\
\hline 20 & 25.9 & 1.75 & 3264.5 & 1.45 & 0.94 & 3316.5 & 2.52 \\
\hline 28 & 25.7 & 1.78 & 3264.5 & 1.42 & 1.07 & 3286.5 & 2.21 \\
\hline
\end{tabular}

concrete, and the higher is the bottom concrete strength. As a result, the new concrete has a higher restraint and stress than the old concrete.

(2) Figure 5(b) shows that as the interval and the elastic modulus increase, the maximum tensile stress of concrete becomes large. In addition, the stress caused by the temperature difference between day and night is high when the interval is long and when the modulus of elasticity is high. Short-term stress overlaid with long-term stress tends to cause great stress at the surface of the concrete, especially if a long interval occurs during winter and when the air temperature abruptly drops because of inadequate insolation. The internal and external temperature difference can cause cracks on the concrete surface. During the low-temperature season, the surface insulation therefore needs to be excellent, and the pouring interval should not be too long to avoid harmful stress when new concrete is poured on old concrete.

4.4. Sensitivity Analysis of the Pouring Temperature. This section examines how pouring temperature affects temperate stress in high-altitude regions, such as Tibet.

Table 6 and Figure 6(a) indicate that (1) the pouring temperature is $12^{\circ} \mathrm{C}$ and $14^{\circ} \mathrm{C}$ in the high restraint zone if concrete is poured during summer. Every $2^{\circ} \mathrm{C}$ increase in the pouring temperature causes the maximum temperature of concrete to increase by about $1.2^{\circ} \mathrm{C}$, the maximum stress to increase by about $0.04 \mathrm{Mpa}$, and the crack resistance safety coefficient to increase by 1.74 and 1.70 . (2) With the same temperature control measures, a high pouring temperature increases the maximum temperature and stress during the end of the first stage of cooling. Figure 6(b) shows that the increase in pouring temperature has hardly any effect on the time of maximum stress. Meanwhile, the stress at the end of the first stage of cooling increases but is still within the safe range.

\section{Temperature Control Measures and Standards during Dam Construction}

5.1. Optimized Option for Temperature Control and Standards. Figure 7 and Table 7 present the suggestions for temperature control measures and standards for Jiexu Dam. These are based on the findings of previous sensitivity studies on construction conditions and temperature control parameters, combined with the actual environment features and specific materials involved, as well as relevant insights from other high-altitude projects. Using the results on number 13 steepsloped water-retaining dam, this study reviews the temperature, stress, and safety of the dam under the recommended temperature control measures and standards. 


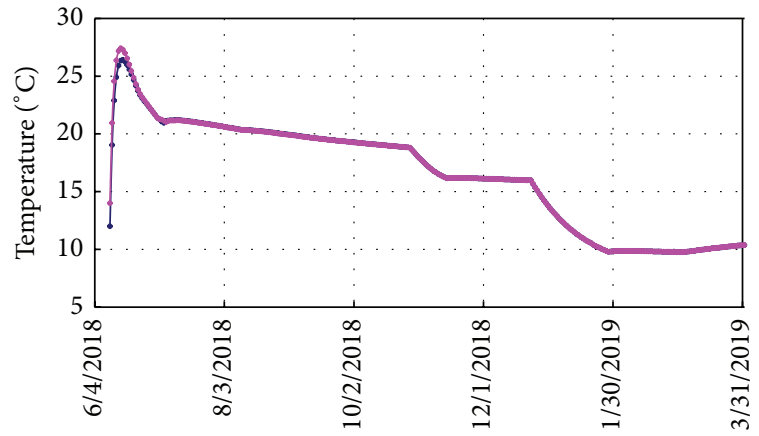

Time (month/day/year)

$\rightarrow 12^{\circ} \mathrm{C}$

$\rightarrow 14^{\circ} \mathrm{C}$

(a) Temperature

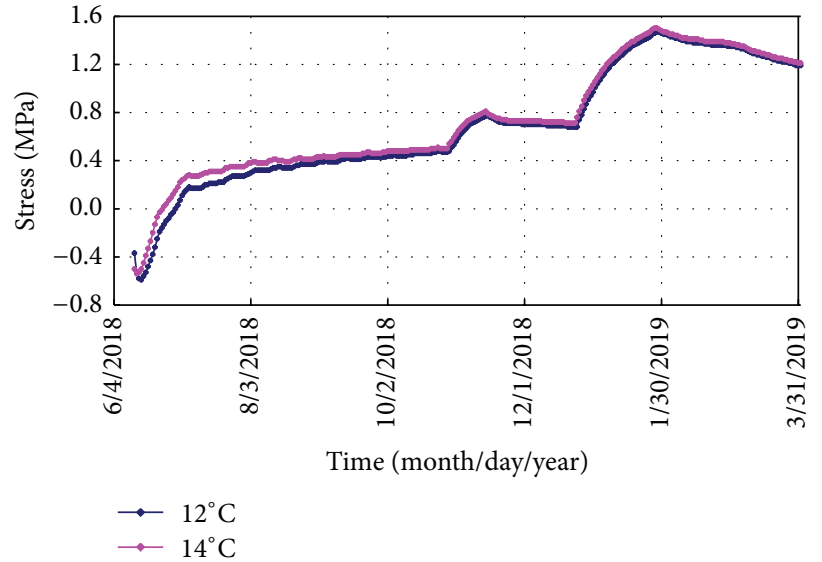

(b) Stress

FIGURE 6: Process curve of concrete temperature and stress in the basic restraint zone under different pouring temperature values.

TABLE 6: Effect of pouring temperature on temperature stress.

\begin{tabular}{|c|c|c|c|c|c|c|c|c|}
\hline \multirow{2}{*}{$\begin{array}{l}\text { Pouring } \\
\text { temperature } \\
\left({ }^{\circ} \mathrm{C}\right)\end{array}$} & \multirow{2}{*}{$\begin{array}{l}\text { Maximum } \\
\text { temperature at the } \\
\text { high restraint zone } \\
\left({ }^{\circ} \mathrm{C}\right)\end{array}$} & \multirow{2}{*}{$\begin{array}{l}\text { Maximum } \\
\text { temperature at the } \\
\text { low restraint zone } \\
\left({ }^{\circ} \mathrm{C}\right)\end{array}$} & \multicolumn{3}{|c|}{$\begin{array}{l}\text { Maximum tensile stress in the } \\
\text { high restraint zone }\end{array}$} & \multicolumn{3}{|c|}{$\begin{array}{l}\text { Maximum tensile stress in the } \\
\text { low restraint zone }\end{array}$} \\
\hline & & & $\sigma_{x}(\mathrm{Mpa})$ & $\begin{array}{l}\text { Elevation } \\
\quad(\mathrm{m})\end{array}$ & $\begin{array}{c}\text { Safety } \\
\text { coefficient }\end{array}$ & $\sigma_{x}(\mathrm{Mpa})$ & $\begin{array}{l}\text { Elevation } \\
\quad(\mathrm{m})\end{array}$ & $\begin{array}{c}\text { Safety } \\
\text { coefficient } \\
k\end{array}$ \\
\hline $12-13-14$ & 26.3 & 27.7 & 1.45 & 3263 & 1.74 & 0.79 & 3283 & 3.00 \\
\hline $14-16-18$ & 27.5 & 27.8 & 1.49 & 3263 & 1.70 & 0.81 & 3283 & 3.12 \\
\hline
\end{tabular}

Note. In the summary of pouring temperature, 12-13-14 shows the temperature in the high restraint zone, low restraint zone, and the free zone.

The length of the bottom of the dam section along the river is $L=45 \mathrm{~m}$. According to specifications [2], counting from the bottom of the dam, the elevation below $0.2 \mathrm{~L}$ is the high restraint zone, the elevation of $0.2 L$ to $0.4 L$ is the low restraint zone, and the elevation above $0.4 \mathrm{~L}$ is the no restraint zone. These specifications are used for the design of the temperature control measures, and their standards are different. The steep slope section of the dam is subject to the constraints of the foundation within a relatively large range. From the perspective of safety, the bottom of $0.2 \mathrm{~L}$ is measured from the top of the slope; the elevation of $9 \mathrm{~m}$ above $3,325 \mathrm{~m}$ is the high restraint zone, the elevation of $3,334 \mathrm{~m}$ to $3,343 \mathrm{~m}$ is the low restraint zone, and the elevation above $3,343 \mathrm{~m}$ is the no restraint zone.

The temperature control measures and standards of the high restraint zone are strict, whereas those of the other zones are less strict, as shown in Figure 7(a) and Table 7. The $9 \mathrm{~m}$ requirement for irrigation areas indicates that to reduce the mutual restraint caused by the temperature difference between the upper and lower irrigation areas during water cooling, the three irrigation areas $(3,300 \mathrm{~m}$ to $3,327 \mathrm{~m}$ ) should be simultaneously cooled from the middle stage of cooling. The water temperature and flow rate are discussed in Table 7. After separation from the high restraint zone, each irrigation area is separately cooled.

5.2. Temperature Stress of the Dam. This section focuses on the temperature and stress of the dam under the recommended temperature control measures and standards. To understand well the scientific rationality of the recommended measures, a comparison is made to show their advantages. The two sets of measures are similar, except that case 1 sets an $18 \mathrm{~m}$ simultaneous cooling zone or one simultaneous cooling zone under a 3,300 m elevation, whereas case 2 added a $27 \mathrm{~m}$ simultaneous cooling zone above the elevation of $3300 \mathrm{~m}$ on the basis of case 1 to further reduce the mutual restraint of the upper and lower zones. A simultaneous cooling zone is defined as follows: starting from the middle stage of cooling, the concrete in the zone begins to cool down simultaneously in order to obtain the coordinate temperature drop and consistent change of concrete, as well as to reduce the mutual restraint and stress; the water temperature and flow rate of the pipe in the simultaneous cooling zone are the same.

From Table 8 and Figures 8 to 10, we can conclude the following.

(1) The number and height of the simultaneous cooling zone does not have a significant effect on the maximum temperature, which is $24.15^{\circ} \mathrm{C}$ for both cases.

(2) Setting one simultaneous cooling zone of $18 \mathrm{~m}$ under an elevation of $3,300 \mathrm{~m}$ and starting the simultaneous cooling from the middle stage result in a small temperature difference between the upper and lower pouring sections, the deformation occurs at the same pace. A relatively small restraint is therefore formed at the base of concrete. The dam section is on a steep slope and is steep in both axial and along-river directions, with the slope height at $43 \mathrm{~m}$. 

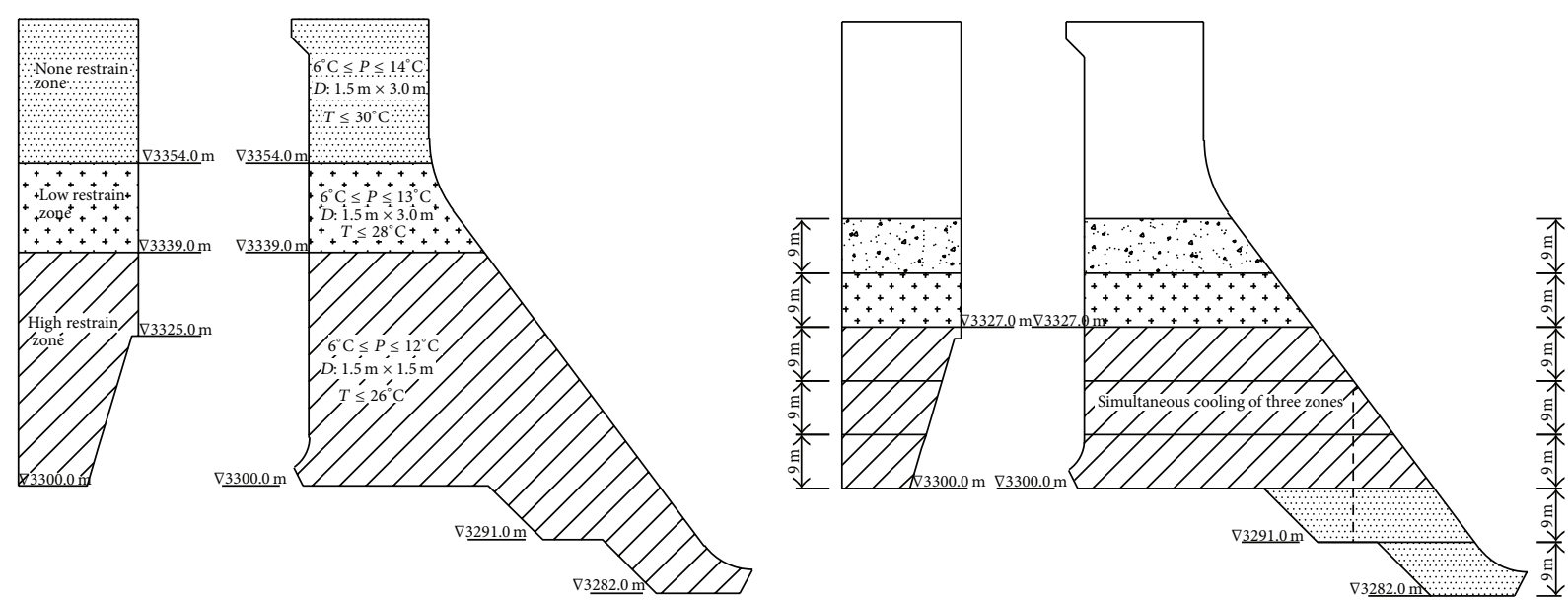

$P$ : pouring temperature (monthly average temperature $+3^{\circ} \mathrm{C}$ )

$D$ : distance between water pipes

$T$ : the maximum allowable temperature of concrete

(a) Arrangement of basic temperature control measures

(b) Cooling method

FIGURE 7: Temperature control measures and cooling methods for the steep slope section of the dam.

TABLE 7: Temperature control measures.

\begin{tabular}{|c|c|c|c|}
\hline \multicolumn{3}{|c|}{ Concrete temperature control measures } & Control index \\
\hline \multicolumn{3}{|c|}{ High restraint zone } & $\leq 12^{\circ} \mathrm{C}$ \\
\hline \multirow[t]{2}{*}{ Pouring temperature } & \multicolumn{2}{|c|}{ Low restraint zone } & $\leq 13^{\circ} \mathrm{C}$ \\
\hline & \multicolumn{2}{|c|}{ No restraint zone } & $\leq 14^{\circ} \mathrm{C}$ \\
\hline \multirow[b]{2}{*}{ Simultaneous cooling } & \multicolumn{2}{|c|}{ Beginning stage of simultaneous cooling } & Middle stage \\
\hline & \multicolumn{2}{|c|}{ Height of the simultaneous cooling } & $\begin{array}{l}18 \mathrm{~m} \text { below elevation } 3,300 \mathrm{~m} \\
27 \mathrm{~m} \text { above elevation } 3,300 \mathrm{~m}\end{array}$ \\
\hline \multirow{3}{*}{$\begin{array}{l}\text { Distance between water } \\
\text { pipes }\end{array}$} & \multicolumn{2}{|c|}{ High restraint zone } & $1.5 \mathrm{~m} \times 1.5 \mathrm{~m}$ \\
\hline & \multicolumn{2}{|c|}{ Low restraint zone } & $1.5 \mathrm{~m} \times 3.0 \mathrm{~m}$ \\
\hline & \multicolumn{2}{|c|}{ No restraint zone } & $1.5 \mathrm{~m} \times 3.0 \mathrm{~m}$ \\
\hline \multirow{12}{*}{ Water pipe cooling } & \multirow{5}{*}{ First stage cooling } & Water temperature & $8.0^{\circ} \mathrm{C}$ \\
\hline & & Flow & $1.5 \mathrm{~m}^{3} \cdot \mathrm{h}^{-1}$ \\
\hline & & Starting age & 0.0 day \\
\hline & & Targeted temperature & $19^{\circ} \mathrm{C}-20^{\circ} \mathrm{C}$ \\
\hline & & Water temperature & $12^{\circ} \mathrm{C}$ \\
\hline & \multirow{2}{*}{$\begin{array}{l}\text { Middle stage of } \\
\text { cooling }\end{array}$} & Flow & $0.8 \mathrm{~m}^{3} \cdot \mathrm{h}^{-1}$ \\
\hline & & Starting age & 30 day-45 day \\
\hline & \multirow{5}{*}{$\begin{array}{l}\text { Second stage } \\
\text { cooling }\end{array}$} & Targeted temperature & $16^{\circ} \mathrm{C}-18^{\circ} \mathrm{C}$ \\
\hline & & Water temperature & $6^{\circ} \mathrm{C}-8^{\circ} \mathrm{C}$ \\
\hline & & Flow & $1.0 \mathrm{~m}^{3} \cdot \mathrm{h}^{-1}$ \\
\hline & & Starting & $\geq 90$ day \\
\hline & & Targeted temperature & $10^{\circ} \mathrm{C}$ \\
\hline \multirow{4}{*}{ Pouring thickness } & \multicolumn{2}{|c|}{ High restraint zone } & $1.5 \mathrm{~m}$ \\
\hline & \multicolumn{2}{|c|}{ Low restraint zone and no restraint zone } & $3.0 \mathrm{~m}$ \\
\hline & \multicolumn{2}{|c|}{ Intervals between layers } & 10 day \\
\hline & \multicolumn{2}{|c|}{ Surface insulation } & $5 \mathrm{~cm}$ vinyl insulation board \\
\hline
\end{tabular}




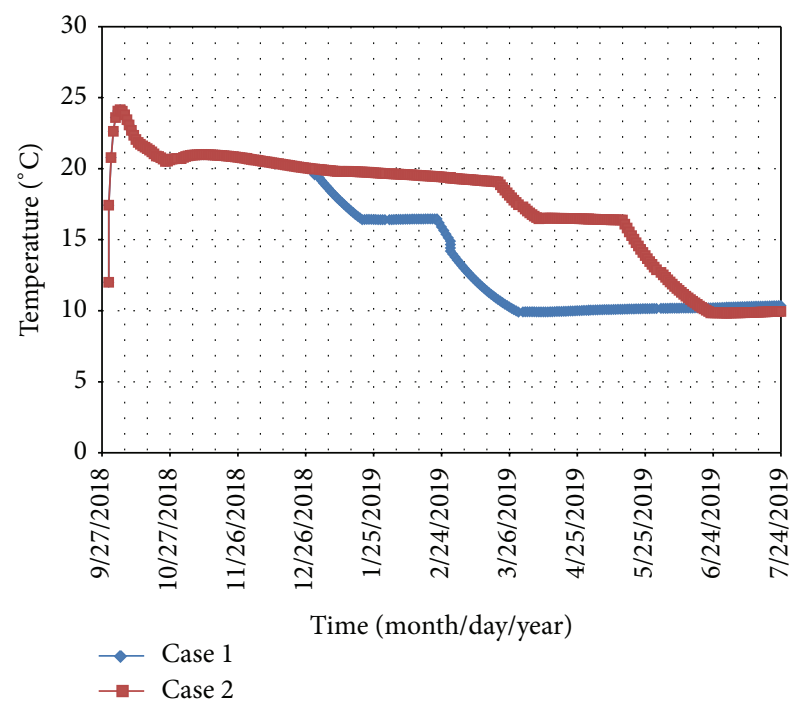

(a) Temperature

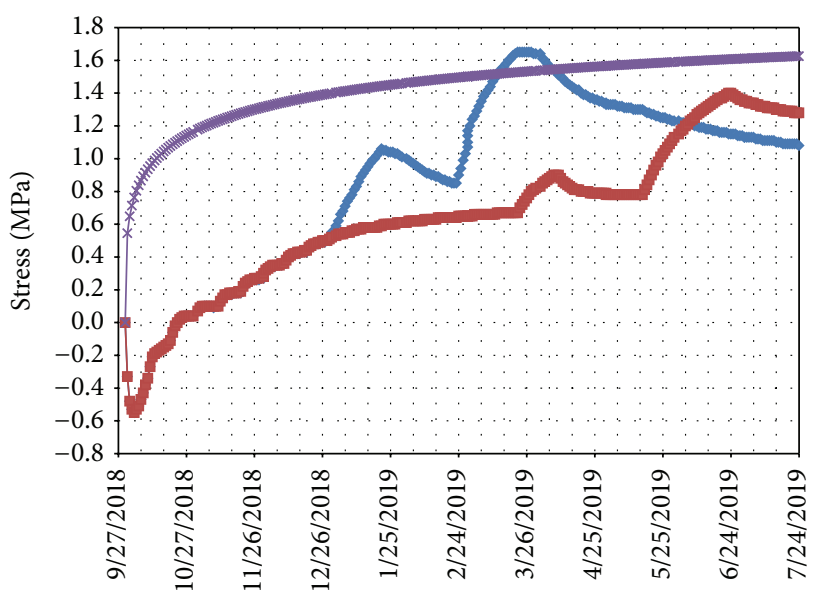

Time (month/day/year)

$\rightarrow$ Case 1

$\rightarrow$ Case 2

(b) Stress

FIGURE 8: Process curves of the concrete temperature and stress at $3304.5 \mathrm{~m}$ elevation for different cases.

TABLE 8: Effect of the amount and height of the simultaneous cooling zone on temperature stress.

\begin{tabular}{|c|c|c|c|c|c|c|}
\hline \multirow[b]{2}{*}{ Case } & \multirow{2}{*}{$\begin{array}{l}\text { Height of the } \\
\text { simultaneous } \\
\text { cooling zone (m) }\end{array}$} & \multirow{2}{*}{$\begin{array}{l}\text { Basic restrain zone } \\
\text { simultaneous cooling } \\
\text { measure }\end{array}$} & \multirow{2}{*}{$\begin{array}{l}\text { Maximum } \\
\text { temperature at the } \\
\text { high restraint zone } \\
\left({ }^{\circ} \mathrm{C}\right)\end{array}$} & \multicolumn{3}{|c|}{ Maximum tensile stress in the high restraint zone } \\
\hline & & & & $\sigma_{x}(\mathrm{Mpa})$ & Elevation $(\mathrm{m})$ & $\begin{array}{c}\text { Safety } \\
\text { coefficient } \\
k\end{array}$ \\
\hline Case 1 & 18 & $\begin{array}{l}18 \mathrm{~m} \text { below the } 3,300 \mathrm{~m} \\
\text { elevation } \\
\text { Simultaneous cooling } \\
\text { during the middle and } \\
\text { second stages }\end{array}$ & 24.15 & 1.65 & 3304.5 & 1.53 \\
\hline Case 2 & $18+27$ & $\begin{array}{l}\text { On the basis of case } 1 \text {, } \\
\text { adding } 27 \mathrm{~m} \text { above the } \\
3,300 \mathrm{~m} \text { elevation }\end{array}$ & 24.15 & 1.40 & 3304.5 & 1.81 \\
\hline
\end{tabular}

Note: (1) $18+27$ means that the first simultaneous cooling zone is $18 \mathrm{~m}$, and the second one is $27 \mathrm{~m}$.

The $18 \mathrm{~m}$ cooling zone is still within the $43 \mathrm{~m}$ slope zone. Therefore, the middle section of the along-river direction of the high restraint zone still bears a large stress at $1.65 \mathrm{Mpa}$. The safety coefficient is only 1.53 .

(3) On the basis of case 1, another simultaneous cooling zone is added above the 3,300 $\mathrm{m}$ elevation level. The $45 \mathrm{~m}$ cooling zone will cover the entire slope, and cooling starts from the middle stage. The change in height and organization of the cooling zone makes the temperature difference along the altitude small and further increases the height of simultaneous deformation. The maximum stress in the high restraint region significantly changes to lower than $1.40 \mathrm{Mpa}$. The safety coefficient increases to 1.82 , which is much better than that of case 1 .

In conclusion, the height and amount of the cooling zone obviously affect the stress of concrete, especially at dam section number 13 , which is very steep. To decrease the stress in the high restraint zone at the second cooling stage, increasing both the amount and the height of the cooling zone on the steep slope to cover the entire height of the steep will decrease the temperature stress caused by the temperature drop between adjoin layers.

\section{Conclusions}

(1) Special and fit-for-purse temperature control measures should be used in building concrete gravity dams in high-altitude provinces, such as Tibet, where the weather conditions are unique, that is, dry thin air, strong sun radiation, and severe temperature difference between day and night. The lack of choices for construction materials because of the location is disadvantageous to crack prevention through temperature control.

(2) The unique weather conditions and disadvantageous temperature control parameters in high-altitude areas entail the need to conduct sensitivity research on construction conditions and parameters in order 


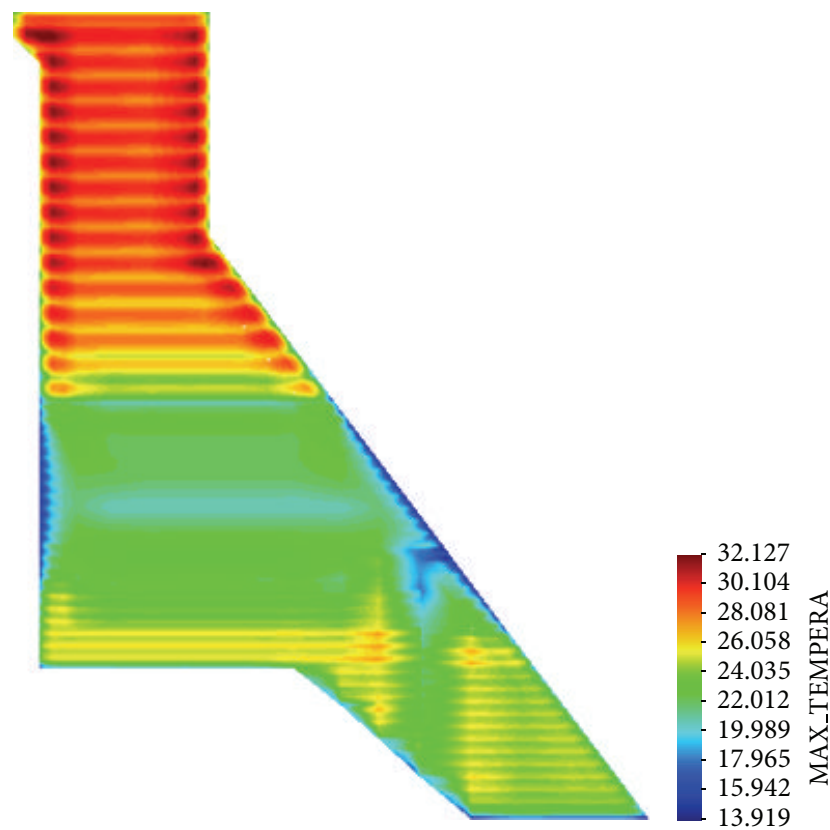

(a) Temperature $\left({ }^{\circ} \mathrm{C}\right)$

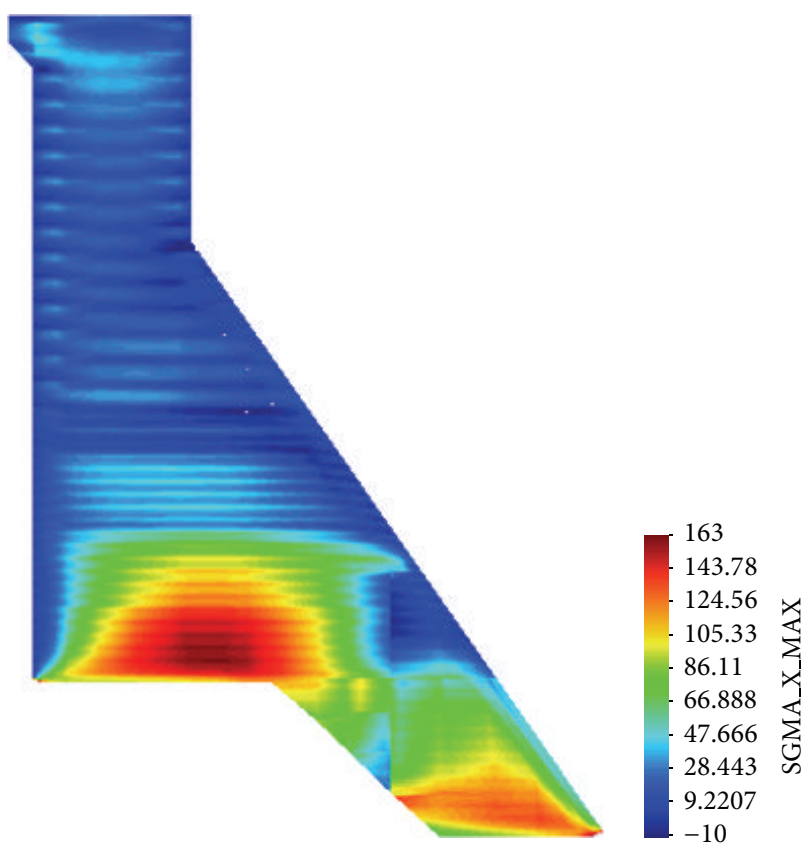

(b) Stress (0.01 Mpa)

FIGURE 9: Envelope diagrams of the concrete temperature and stress in the middle section of the dam in case 1.

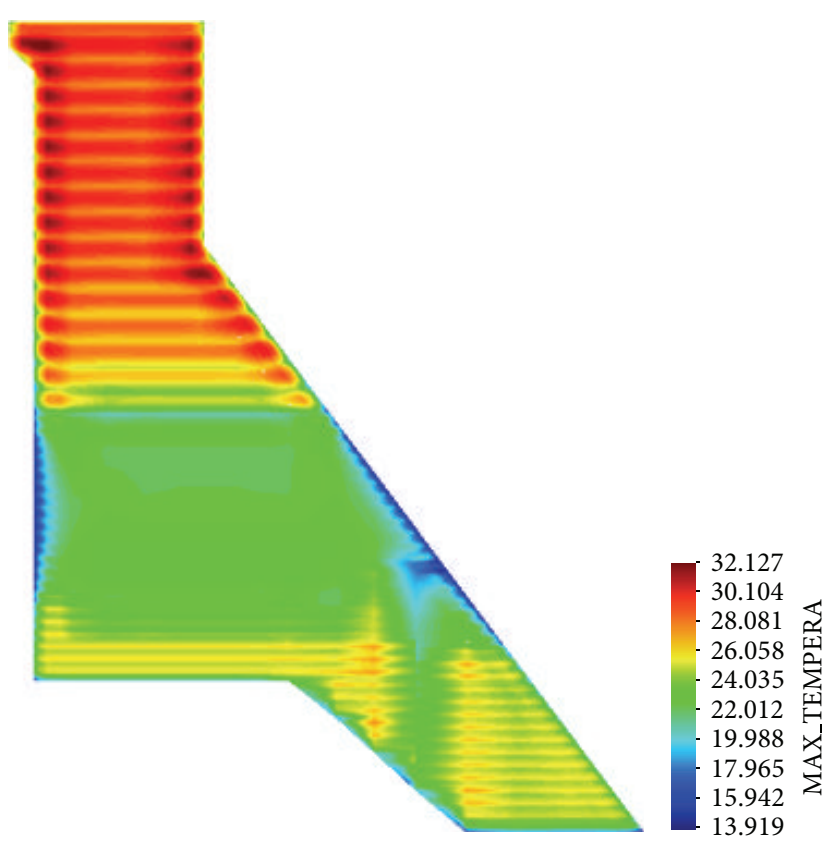

(a) Temperature $\left({ }^{\circ} \mathrm{C}\right)$

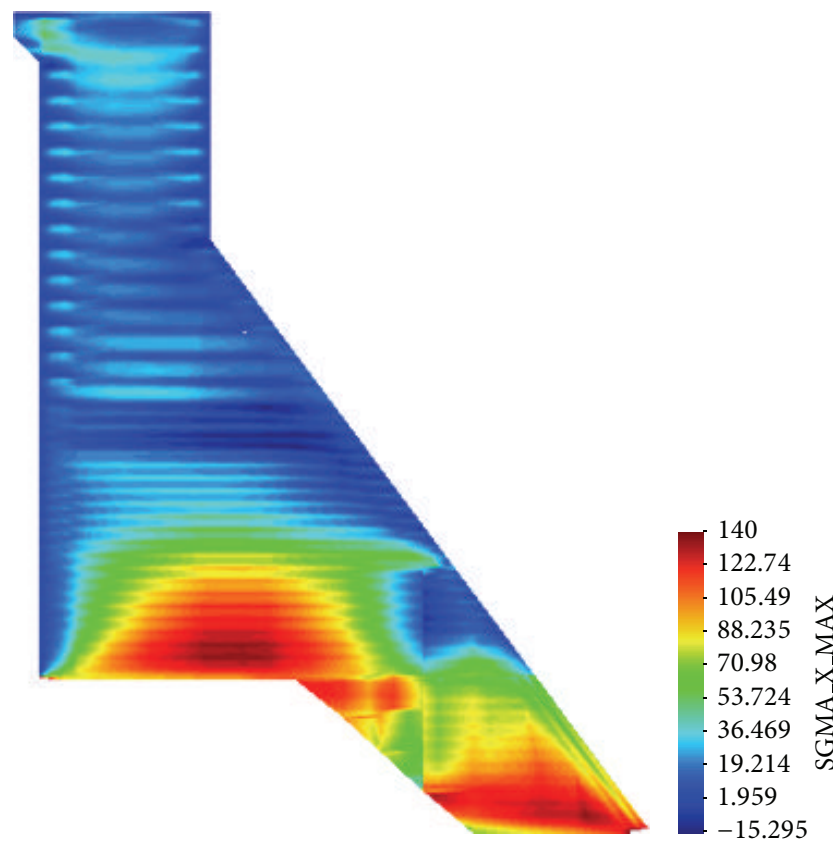

(b) Stress (0.01 Mpa)

FIGURE 10: Envelope diagrams of the concrete temperature and stress in the middle section of the dam in case 2.

to determine the mechanism of influence involved. Research shows that stress is highest when the pouring is done during autumn, $1.5 \mathrm{~m}$ is the ideal thickness for the high restraint zone, long pouring intervals should be avoided, and the pouring temperature should be strictly controlled.
(3) The height and amount of the simultaneous cooling zone considerably affect stress. The simultaneous cooling zone can reduce the temperature difference in the height direction, coordinate the deformation, and decrease the mutual restraint of the upper and lower zones and the temperature stress caused by 
the temperature drop between adjoin layers. Within the allowed conditions, increasing the height of the cooling zone, especially on a slope, is advised.

(4) The experience in the temperature control of Zangmu, which is the same concern confronted in Jiexu, shows that intelligent water flow makes the internal cooling process rational and optimized. Real-time temperature examination indicates that feedback, calculation, and flow adjustment, as well as the automatic intervention of cooling water flow, are realized to prevent cracks through control of the temperature process, such as avoidance of high-temperature increases and rapid temperature drops.

\section{Conflict of Interests}

The authors declare that there is no conflict of interests regarding the publication of this paper.

\section{Acknowledgments}

The authors acknowledge the support and funding provided by the National Key Basic Research Program of China (973 Program) (2013CB036406, 2013CB035904), the Key Projects in the National Science and Technology Pillar Program during the Twelfth Five-year Plan Period (2013BAB06B02), the Special Scientific Research Project of the China Institute of Water Resources and Hydropower Research, and the Special Scientific Research Project of the State Key Laboratory of Simulation and Regulation of Water Cycle in River Basin.

\section{References}

[1] P. Hu, P. Yang, G. Zhang, Z. Ren, and L. Lei, "Research on temperature control and crack prevention on double curvature arch dam in Laxiwa Hydropower Station," Hydropower, vol. 33, no. 11, pp. 51-54, 2007.

[2] SL 282-2003, Design Guidelines of Concrete Arch Dam, 2003.

[3] T. Zhang and J. Chen, "Study of special construction measures in high altitude and cold regions," Hunan Water Resources and Hydropower, vol. 6, pp. 48-51, 2010.

[4] A. Liu, "Concrete construction in winter in North Tibet, Jilin water resource and hydropower," Extended Heat Reserve, vol. 5, pp. 1-3, 2000.

[5] Z.-H. Wang, Y.-M. Zhu, and S.-P. Yu, "Study on temperature control and crack prevention of thin-walled concrete structure," Xian Construction Technology University Journal, vol. 39, no. 6, pp. 773-778, 2007.

[6] D. Yuan, "Reasons of cracks in concrete's underground part and prevention methods," Construction Technologies, no. 4, pp. 9293, 2012.

[7] B. Ding, G. Wang, S. Huang et al., "A review on causes of cracking in domestic concrete dams and preventive measures," Water Resources and Hydropower Engineering, no. 4, pp. 12-18, 1994.

[8] N. Shi, J. Ouyang, R. Zhang, and D. Huang, "Experimental study on early-age crack of mass concrete under the controlled temperature history," Advances in Materials Science and Engineering, vol. 2014, Article ID 671795, 10 pages, 2014.

[9] Z. Zhang, X. Guo, and R. Du, "Analysis of hydration heatinduced stresses and cracks in massive concrete walls," Journal of Hohai University, vol. 30, no. 5, pp. 12-16, 2002.

[10] G. De Schutter, "Finite element simulation of thermal cracking in massive hardening concrete elements using degree of hydration based material laws," Computers and Structures, vol. 80, no. 27-30, pp. 2035-2042, 2002.

[11] C. Bailey and M. Cross, "A finite volume procedure to solve elastic solid mechanics problems in three dimensions on an unstructured mesh," International Journal for Numerical Methods in Engineering, vol. 38, no. 10, pp. 1757-1776, 1995.

[12] Y. Ballim, "A numerical model and associated calorimeter for predicting temperature profiles in mass concrete," Cement and Concrete Composites, vol. 26, no. 6, pp. 695-703, 2004.

[13] A. I. H. Malkawl, S. A. Mutasher, and T. J. Qiu, "Thermalstructural modeling and temperature control of roller compacted concrete gravity dam," Journal of Performance of Constructed Facilities, vol. 17, no. 4, pp. 177-187, 2003.

[14] P. Léger and M. Leclerc, "Hydrostatic, temperature, timedisplacement model for concrete dams," Journal of Engineering Mechanics, vol. 133, no. 3, pp. 267-277, 2007.

[15] F. Zhu and K. Li, "Modeling heat and moisture transfer within porous textiles under high temperature gradients," Advanced Materials Research, vol. 455-456, pp. 1136-1139, 2012.

[16] J. Komonen and V. Penttala, "Influence of admixture type and concrete temperature on strength and heat of hydration of concrete," in Proceedings of the 10th International Congress on the Chemistry of Cement, H. Justnes, Ed., vol. 3, pp. 1-8, Amarkai $\mathrm{AB}$ and Congrex Goteborg AB, Gothenburg, Sweden, 1997.

[17] A. K. Schindler, Concrete hydration, temperature development, and setting at early-ages [Ph.D. thesis], University of Texas at Austin, Austin, Tex, USA, 2002.

[18] D. Lelièvre, V. Nicolas, and P. Glouannec, "Numerical modeling of heat and mass transfer in porous materials during drying and shrinkage," in COMSOL Conference, 2012.

[19] Z. P. Bazant and S. Baweja, "Creep and shrinkage prediction model for analysis and design of concrete structures-model $\mathrm{B}_{3}$," Materials and Structures, vol. 28, no. 6, pp. 357-365, 1995.

[20] Z. Zuo, Y. Hu, Y. Duan, and J. Yang, "Simulation of the temperature field in mass concrete with double layers of cooling pipes during construction," Journal of Tsinghua University, vol. 52, no. 2, pp. 186-228, 2012.

[21] B. Zhu, Thermal Stresses and Temperature Control of Mass Concrete, China Electric Power Press, Beijing, China, 1998. 


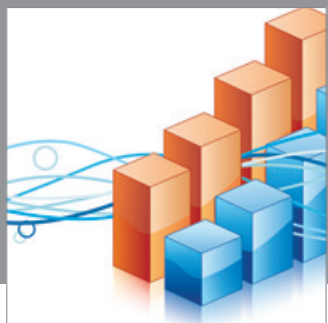

Advances in

Operations Research

mansans

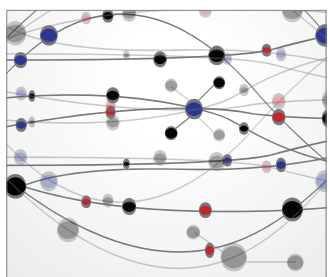

The Scientific World Journal
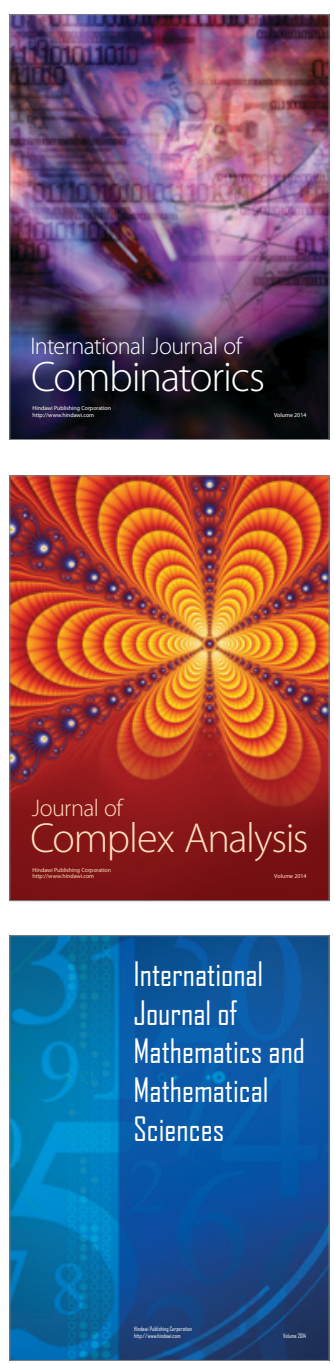
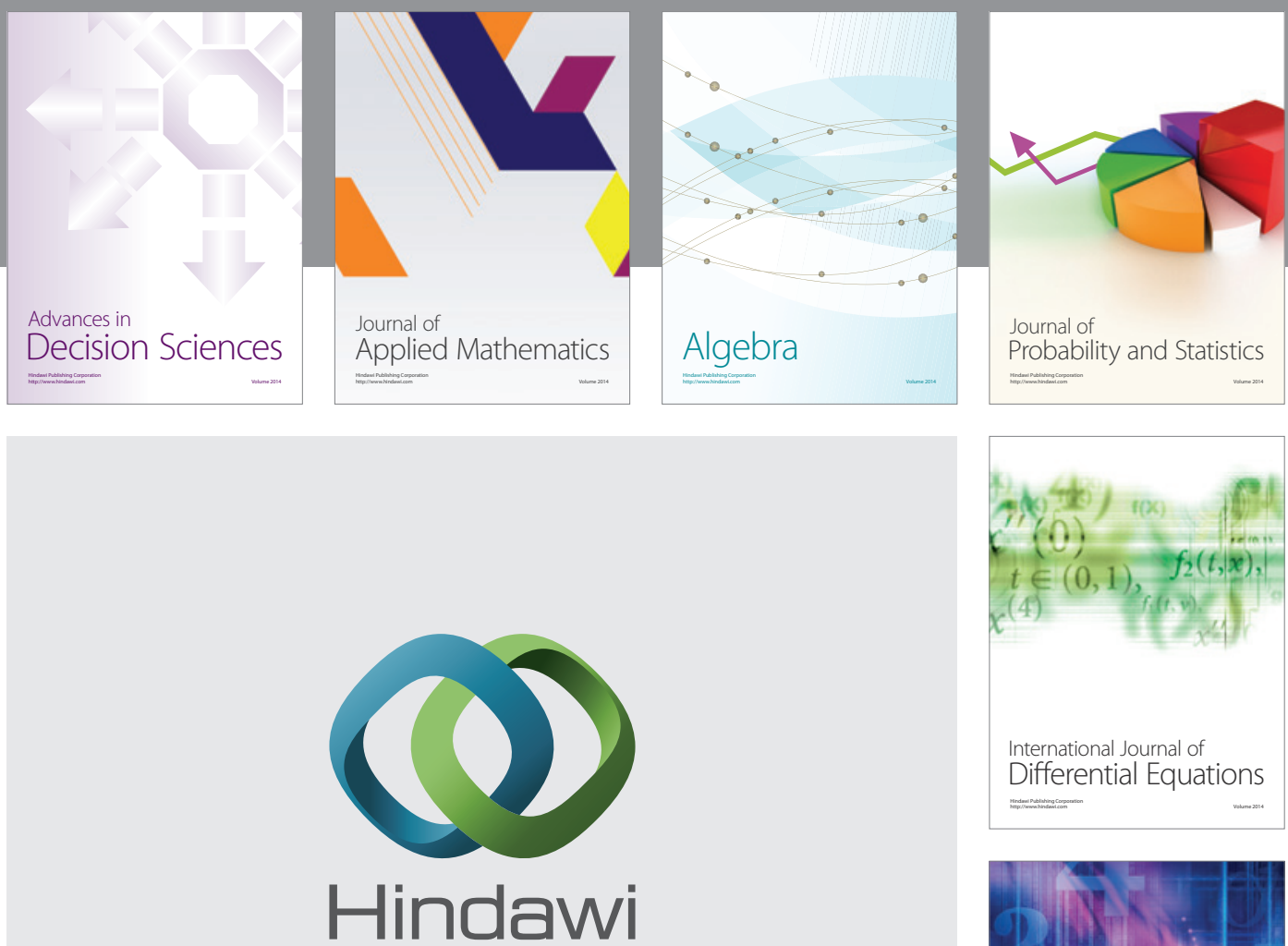

Submit your manuscripts at http://www.hindawi.com
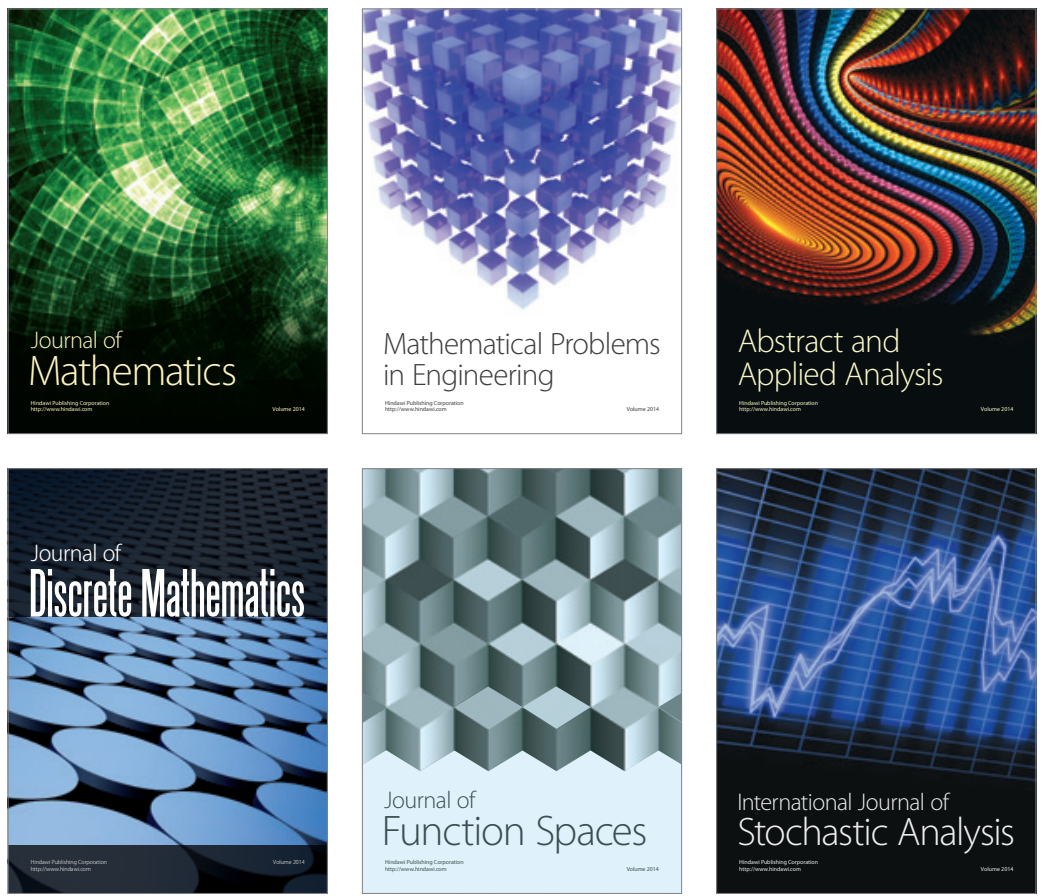

Journal of

Function Spaces

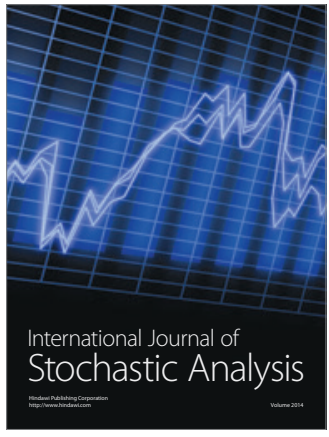

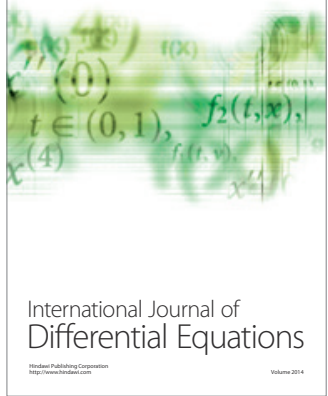
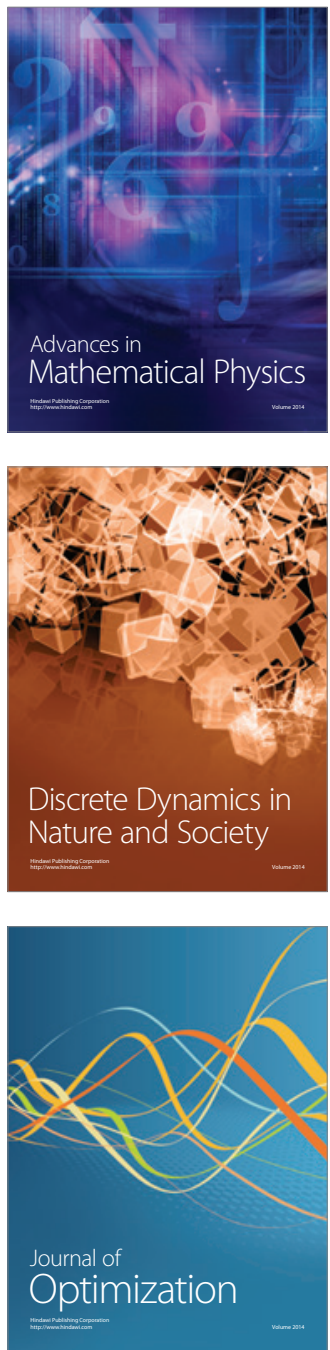